\title{
The Critical Success Factors of Biotechnology and Pharmaceutical Industry in SIAT---Integration Entrepreneur, Entrepreneurial Opportunity and Entrepreneurial Resource Perspective
}

\author{
Hsin-Po Chen ${ }^{a}$, Chia-Nan Wang ${ }^{b}$ and Ming-Hsien Hsueh ${ }^{c}$ \\ Department of Industrial Engineering and Management, National Kaohsiung University of Applied \\ Sciences, Kaohsiung, Taiwan \\ ahsinpo2@gmail.com, ${ }^{b}$ cn.wang@cc.kuas.edu.tw, ${ }^{c}$ mhhsueh@kuas.edu.tw
}

\begin{abstract}
This research based on social capital and human capital discusses and opportunity Identification and entrepreneurial motivation and Incubator Counseling that the factors influence on newly nascent entrepreneur's success and the critical success factors of Biotechnology and Pharmaceutical Industry in SIAT. Applying the data of SIAT enterprise as empirical samples, the object of the study is the critical success factors of Biotechnology and Pharmaceutical Industry in SIAT. The purpose of the study is to illustrate how to establish and initiate the enterprise activities and basic conditions and why the businesses can be work out by the presentations of organizations' activities. This study uses the empirical results to demonstrate the successful factors of newly nascent entrepreneurs on their businesses and to illustrate the meaning and practical assistance of the data of SIAT enterprise. The 4 most important criterion that the analytics value are: Human Capital makes up 0.4295 of the overall importance; management experience make up 0.162 of the overall importance; Business network make up 0.0693 of the overall importance; Money \& Status makes up the 0.0927 of the overall importance.; And administrative services support makes up the 0.07 of the overall importance.
\end{abstract}

Keywords: Human Capital; Social Capital; Opportunity Identification; Entrepreneurial Motivation; Incubator Counseling.

\section{Introduction}

Formal concept of business incubators in the United States began in 1959, when Joseph • Mancuso opened the Batavia Industrial Center in Batavia, New York, warehouse, becoming an incubator Batavia Industrial Center is beyond the enterprise. It is the first customer of a chicken's end called a business incubator. Today, there are incubators throughout the country, all with different formats to meet the needs of a variety of small startups. National Business Incubation Association, a member of the incubator program, counting more than 7,000 incubators worldwide, of which 130 are in Taiwan.

Purpose of this study was to investigate the integration of entrepreneurs, entrepreneurial opportunities and entrepreneurial resource perspectives to explore the incubator center key success factors of Biotechnology and Pharmaceutical Industry, explained the research purpose of this study is hereby statement will be as follows: I. Review of human capital, social capital, entrepreneurial motivation and bred counseling literature, there by intended to Entrepreneurial Opportunities, integrate entrepreneurs and resources to explore the key point of the incubator center of the new venture's initial success factors hierarchy. Second, the difference between the center and explore the incubator tenant companies cognition factors. Third, through the experience of the entrepreneur has been applied and theoretical analysis, and accordingly investigate the incubator center of the critical success factors of new ventures to generate a key factor in whether a specific entrepreneurial success. Fourth, through the application of AHP analysis of human capital, social capital, entrepreneurial motivation and counseling related rights bred various factors heavy, and accordingly a key factor in this view whether the relative weight of entrepreneurial success. Fifth, summarized the results of this study, propose specific practical recommendations for future researchers. 


\section{Literature Review}

Human capital: 1960 Nobel laureate in economics, Schultz proposed human capital term. Schultz pointed out that people have the ability and knowledge can be regarded as a capital investment, enterprises through formal education, job training, health care and other accumulated experience and human capital, will be able to improve the quality of labor, and increase productivity [1]. Becker [2] believes that human capital is the part of employees' productivity is also a corporate asset. Education and training are the two most important investment in human capital, not only improve the quality of staff and enhance ROI. In the organization "people" are the core resources, the organization is a key factor in maintaining competitiveness and organizational performance. The entrepreneurial experience is divided into three parts, namely entrepreneurs starting experience, management experience and industry specific experience. Following is foregoing will explore entrepreneurial experience is divided into blocks: (a) Entrepreneurial start Experience. (b)Management experience. (c)Industry-specific experience. (d) Educational Background.

Social capital: Social capital is a quality derived from the structure of an individual's network relationships - it is not an intrinsic characteristic of an individual. Ownership of the network relationship is jointly held among the members of a network and is not solely the property of the individual. Review the literature of social capital, the entrepreneurial process involves a lot of information and access to resources, so one man alone is very difficult to accomplish, so through the accumulation and use of social capital will be able to help entrepreneurial tendencies. This study will use the concept Davidson [3], the social capital perspective internal social capital and external social capital as the theoretical basis of this study together with the theoretical model decision after the interview, (a) including market information needed marketing information, (b) business network business network, (c) relatives and friends are encouraged to positively encourage,(d) support government policy.

Entrepreneurial Motivation: Maslow's hierarchy of needs is a theory in psychology proposed by Abraham Maslow in his 1943 paper "A Theory of Human Motivation" in Psychological Review. Maslow subsequently extended the idea to include his observations of humans' innate curiosity. His theories parallel many other theories of human developmental psychology, some of which focus on describing the stages of growth in humans. Maslow used the terms Physiological, Safety, Belongingness and Love, Esteem, Self-Actualization and Self-Transcendence needs to describe the pattern that human motivations generally move through. Interviews have been entrepreneurs use the information obtained will twenty-eight variables and Maslow's hierarchy of needs fall into four motivational factors were: money status, self-realization, survival escape, opportunity interest, its implications are as. Considering the study was stationed Incubation Center entrepreneurs, mainly due to its entrepreneurial behavior can be successfully completed by the assistance of the Government, and therefore (a) Money Status. (b) Self-actualization. (c)Escape. (d)Freedom as the study of sub-dimensions of Entrepreneurial Motivation.

Incubation counseling: Small and Medium Enterprise Administration of Taiwan believe that the establishment of local resources in the background and they all have the same set up its counseling Innovation Incubation Center, and incubation centers around the operational characteristics of its content and services, and then a nutshell, a full range of services they provide is as follows:(a) Administrative Service Support. (b) Service Network Design. (c) Hardware and software integrity. (d) Parent organization Support.

Taiwan incubation center operators can roughly divided according to their academic, nonprofit research institutions, public sector, and private operator type; addition, according to the main service area Incubation Center can be provided to tenant companies into technical and business Incubation Center. As of 2012, the national total of 131 incubation centers, from 86 to 102 cumulative subsidy 113 , to the vast majority of academic incubators, the reason was due to the use of existing space colleges, equipment, manpower, greatly reducing set-up costs and can therefore expect to reach production, learning and research exchanges and close cooperation relationship.Incubation counseling literature review, this study using domestic services of outside experts to provide 
incubation centers, plus bred counseling interview after the decision theoretical model including administrative services required to support, service network design, hardware and software support to improve sexual and maternal energy.

\section{Methodology}

The Analytical Hierarchy Process is a decision making tool. This method is a multi-criteria decision making and was introduced by Saaty [4].This tool can be useful in solving decision problems, which involve too many decision criteria.

The AHP uses a multi-level hierarchical structure of objectives, criteria, sub criteria, and alternatives. Spatial Multi-criteria decision problems usually involve a series of spatial situations that should be evaluated based on several different criteria. The consistency ratio indicates the probability that the matrix rating were randomly generated. However, perfect consistency rarely occurs in real life, therefore CR should evaluate, thus if as a result of CR is greater than 0.10 , this means that the weights should evaluate again, and if the CR is less than 0.1 , this means that the weights are acceptable.

The CR coefficient is calculated as follows, the first step is calculated CI which can estimated with the next equation;

$$
C I=\frac{(\lambda \max -n)}{n-1}
$$

Where;

CI: Consistency index,

$: \Sigma$ of the products between each element of the priority vector and column totals.

: Number of factors

Then;

Where; RCI is given by the following table:

Table 1 RCI values for different values of $n$

\begin{tabular}{|ccccccccc|}
\hline $\mathbf{n}$ & 1 & 2 & 3 & 4 & 5 & 6 & 7 & 8 \\
RCI & 0 & 0 & 0.58 & 0.9 & 1.12 & 1.32 & 1.41 & 1.45 \\
\hline \multicolumn{8}{c}{ Source: Saaty (1977) }
\end{tabular}

Finally, the last step is to obtain the overall rating, in this part the relative weights of decision ele-ments are aggregated in order to obtain an overall rating and is given by the next equation;

$$
A_{A H P}^{i}=\sum_{j=1}^{N} a_{i j} w_{j}, \text { for } i=1,2,3, \ldots M
$$

Where;

$A_{A H P}^{i}$ : Total weight of AHP

$\mathrm{a}_{\mathrm{ij}}$ : Weight of the $\mathrm{i}$ - th alternatives associated to the $\mathrm{j}$ - th attribute

$\mathrm{W}_{\mathrm{j}}$ : Weight of the $\mathrm{j}$ - th attributes

$\mathrm{N}$ : Number of attributes

In this study, the recovered AHP questionnaire for consistency index and consistency ratio test, AHP questionnaire to determine whether they have reasonable, if the test results show that reasonable, , then further for "evaluation criteria" and "evaluation indicators" AHP questionnaire within the relative weight to be re-calculated to strike the empirical analysis of the results.

\section{Empirical analysis}

Release of 8 parts of the AHP questionnaire and recovering 8 parts, and according to the results of this test showed that 8 parts of this questionnaire are CI $\leqq 0.1$ AHP CR $\leqq 0.1$ and the questionnaires. 
Table 2 table of relative weights

\begin{tabular}{|c|c|c|c|}
\hline Level 1 & Factor weights & C.R. & Order \\
\hline human capital & 0.4295 & 0.1 & 1 \\
\hline Social capital & 0.1935 & 0.1 & 3 \\
\hline Entrepreneurial Motivation & 0.2065 & 0.1 & 2 \\
\hline Incubation counseling & 0.1705 & 0.1 & 4 \\
\hline
\end{tabular}

Table 3 table of relative weights

\begin{tabular}{|c|c|c|c|}
\hline Level 2 & Factor weights & C.R. & Order \\
\hline start-up experience & 0.1024 & 0 & 3 \\
\hline management experience & 0.162 & 0 & 1 \\
\hline industry-specific experience & 0.104 & 0 & 2 \\
\hline Educational Background & 0.0611 & 0 & 4 \\
\hline
\end{tabular}

Table 4 table of relative weights

\begin{tabular}{|c|c|c|c|}
\hline Level 2 & Factor weights & C.R. & Order \\
\hline marketing information & 0.0519 & 0.01 & 2 \\
\hline business network & 0.0693 & 0.01 & 1 \\
\hline positively encourage & 0.0274 & 0.01 & 4 \\
\hline policy support framework & 0.0449 & 0.01 & 3 \\
\hline
\end{tabular}

Table 5 table of relative weights

\begin{tabular}{|c|c|c|c|}
\hline Level 2 & Factor weights & C.R. & Order \\
\hline Money \& Status & 0.0927 & 0.01 & 1 \\
\hline Self-actualization & 0.0464 & 0.01 & 2 \\
\hline Escape & 0.0278 & 0.01 & 4 \\
\hline Freedom & 0.0396 & 0.01 & 3 \\
\hline
\end{tabular}

Table 6 table of relative weights

\begin{tabular}{|c|c|c|c|}
\hline Level 2 & Factor weights & C.R. & Order \\
\hline Administrative Service Support & 0.07 & 0.01 & 1 \\
\hline Service Network Design & 0.0518 & 0.01 & 2 \\
\hline Hardware and software integrity & 0.0338 & 0.01 & 3 \\
\hline Parent organization Support & 0.0149 & 0.01 & 4 \\
\hline
\end{tabular}

\section{Conclusion}

In this study, once stationed received counseling bred manufacturers the incubator center for example, its purpose in the empirical "integrate entrepreneurs, Entrepreneurial Opportunities and resources to explore the key point of the incubator center of Biotechnology and Pharmaceutical Industry new venture success factors measure of model development, was concluded by the Institute, it is described as follows.

Human capital aspects: The incubator center in the critical success factors of The incubator center in the critical success factors of new ventures, the "human capital" dimension "technical accumulated experience" the most influential factors, the first layer is the main criteria for assessing the "human capital" is the consistency of respondents identified new ventures, the "human capital" dimension "technical accumulated experience" the most influential factors, the first layer is the main criteria for assessing the "human capital" is the consistency of respondents identified the most important main criteria as shown in Table 2, in assessing indicators "technical accumulate experience" of respondents importance of consistency in Table 3. Confirmed stationed off the incubator center in entrepreneurial new ventures home before has a "technical cumulative experience" for entrepreneurial success has important influence on their business conditions precedent that itself has considerable "technical accumulate experience" and thus enhance the scientific industry. Like the spirit of science to industry for the introduction of advanced technology for industrial and scientific and technical personnel in 
order to encourage domestic industrial technology research and innovation, and promote the development of advanced technology industry. After the experience accumulated with technology entrepreneurs less likely to result when the reality from the industry, the lack of industry experience, among other factors, caused the failure cause. In particular, every enterprise must face the uncertainty in the business environment, conduct surveillance side of environmental technologies, information collection and processing techniques to cope with the changing environment. Irrespective of whether the discipline, industry, raw materials and equipment suppliers, the entrepreneurs themselves previously accumulated high technology and associated piping and technical knowledge of the industry, the market faces the more information provided.

Social capital aspects: The key to the incubator center new venture success factors, "social capital" dimension to factor the " business network " the more significant influence as shown in Table 4, in the first layer of the main criteria for assessing the "social capital" under evaluation indicators, the survey consider that a " business network " as the most important. Biotechnology and Pharmaceutical Industry is technology-intensive, highly innovative and high value-added industries. Especially in the pharmaceutical industry. Because biotech products subject to regulatory control. Resulting in long product development, funds raised is not easy because high in-vestment risk. Difficult for many businesses to support to the stage to market, so efficient R\&D performance is important foundation of the development of the biotechnology pharmaceutical industry.

Entrepreneurial Motivation aspects: The key to the incubator center new venture success factors, entrepreneurial motivation dimension to factor "money position" of the more influential as shown in Table 5. Analysis showed that evaluation indicators "entrepreneurial motivation" under the survey were considered as "money position" as the most important. This data shows that most of the observed entrepreneur's respondents believed that "money position" on entrepreneurial motivation is the most important, "survival evasion" is the most important option, meaning all those who entered the incubator center of these entrepreneurs. Most are not evade the issue in order to survive to open up a new career, but to be able to pursue higher monetary position.

Incubation counseling aspects: The key to success in the incubator center factor in the new venture, bred counseling dimension to the factors of administrative services support more influential as shown in Table 6 , the analysis showed that bred counseling under evaluation indicators, survey were considered as administrative support services as the most important. This data shows that most of the observed entrepreneurs re-spondents believed that the entrepreneurial process is important for administrative services to support entrepreneurs throughout bred counseling for administrative services stationed vendor support, to help set up the company or commercial registration or conduct space equipment and administrative management support (including executive management, data management vendors and property management and other matters). If the thought of a counseling bred pyramid, in which administrative services that work might just be at the bottom of the pyramid, even though it is heavy and compared with no added value. But for entrepreneurs to, the cumbersome administrative work will be its most troubled by the entrepreneurial process.

\section{References}

[1] Schultz, T. W.(1961). Investment in Human Capital. American Economic Review, 51(1), 1-17.

[2] Becker, G. S. (1964). Human Capital: A Theoretical and Empirical Analysis with Special Reference to Education. Chicago, IL: NBER, University of Chicago Press.

[3] Davidsson, P. \& Honig, B., (2003), The Role of Social and Human Capital among Nascent Entrepreneurs, Journal of Business Venturing, 18, 301-331.

[4] Saaty , T.L. (1990). An Exposition of the AHP in Reply to the Paper 'Remarks on the Analytic Hierarchy Process', Management Science, 36: 259-268. 